\title{
Multiplicação do sabugueiro por estaquia de acordo com o tipo de estaca e concentração de ácido indolbutírico
}

\author{
Cristiano Hossel, Alexandre Defaveri, Dalva Paulus, Jean Tides, Jessica Scarlet Alves De Oliveira Hossel
}

Universidade Tecnológica Federal do Paraná - UTFPR, Pato Branco, PR. E-mail: cristianohossel@gmail.com

\begin{abstract}
Resumo
O objetivo foi avaliar a multiplicação do sabugueiro (Sambucus australis) de acordo com o tipo de estaca e concentração de ácido indolbutírico (AIB) pela técnica de estaquia. O trabalho foi realizado na Unidade de Ensino e Pesquisa Horta de Plantas medicinais, da Universidade Tecnológica Federal do Paraná - Câmpus Dois Vizinhos (PR). O delineamento experimental foi inteiramente casualizado, em esquema fatorial $2 \times 5$ (tipo de estaca $x$ concentração de AIB), com 4 repetições de 10 estacas por unidade experimental. Os ramos foram preparados em estacas de $8 \mathrm{~cm}$, mantendo-se um par de folhas reduzido a $25 \%$ do tamanho original. As estacas foram preparadas de dois tipos de ramos (Herbácea e Semi-lenhosa). Posteriormente a base das estacas foram tratadas com solução de AIB, nas concentrações 0, 500, 1000, 1500 e $2000 \mathrm{mg} \mathrm{L}^{-1}$, durante 10 segundos e colocadas em tubetes redondos contendo substrato comercial. Aos 60 dias da implantação do experimento foram avaliados o enraizamento das estacas, número médio de raízes por estaca, comprimento médio de raiz, número médio de brotações por estaca, comprimento médio das brotações, massa de matéria fresca da parte aérea e radicular e massa de matéria seca da parte aérea e radicular. Das estacas enraizadas, foram escolhidas 5 aleatoriamente de cada tratamento, sendo replantadas em tubetes para avaliar a sobrevivência 30 dias após a avaliação. Para a multiplicação do sabugueiro (Sambucus australis) pela técnica de estaquia não é recomendada a aplicação exógena de AIB, de maneira que as estacas podem ser confeccionadas de material herbáceo e semi-lenhoso.
\end{abstract}

Palavras-chave: propagação vegetativa; Sambucus australis; enraizamento.

Multiplication of the sabugueiro by stacking according to the type of cutting and concentration of indolbutyric acid

\begin{abstract}
The objective of this study was to evaluate the multiplication of elderberry (Sambucus australis) according to the cutting type and indolbutyric acid concentration (IBA) by cutting technique. The work was carried out at the Horta Teaching and Research Unit of Medicinal Plants, Universidade Tecnológica Federal do Paraná Câmpus Dois Vizinhos (PR). The experimental design was completely randomized, in a $2 \times 5$ factorial scheme (stake type $\mathrm{x}$ IBA concentration), with 4 replicates of 10 cuttings per experimental unit. The branches were prepared on $8 \mathrm{~cm}$ cuttings, keeping a pair of leaves reduced to $25 \%$ of the original size. The cuttings were prepared from two types of branches (Herbaceous and Semi-woody). Subsequently the base of the cuttings were treated with IBA solution at the concentrations $0,500,1000,1500$ and $2000 \mathrm{mg} \mathrm{L}^{-1}$, for 10 seconds and placed in round tubes containing commercial substrate. Sixty days after the implantation of the experiment were evaluated the rooting of the cuttings, average number of roots per cutting, average length of root, average number of shoots per shoot, average shoot length, fresh shoot and root mass and dry matter of shoot and root. From the rooted cuttings, 5 were chosen randomly from each treatment and were replanted in tubes to evaluate the survival 30 days after the evaluation. For the multiplication of the elderberry (Sambucus australis) by the cutting technique, the exogenous application of IBA is not recommended, so that the cuttings can be made of herbaceous and semi-woody material.
\end{abstract}

Key words: vegetative propagation; Sambucus australis; rooting. 


\section{Introdução}

As plantas servem de utilização dos seres humanos, desde alguns séculos anteriores a Cristo, sendo primeiramente utilizado apenas para consumo e posteriormente para a cura de enfermidades (MARODIN; BAPTISTA, 2001). Atualmente, grande quantidade de espécies de plantas são utilizadas para fins medicinais, no desenvolvimento de medicamentos, considerando-se que mais de $50 \%$ de todos os medicamentos disponíveis são derivados de produtos naturais, chegando a $75 \%$ na área de tratamento contra o câncer (NEWMAN; CRAGG, 2016).

Dentre as famílias de maior importância está a Adoxaceae, a qual está compreendida o gênero Sambucus (JUDD et al., 2009), que apresenta cerca de 25 espécies distribuídas em regiões temperadas e subtropicais (SCOPEL et al., 2007).

Dentre as espécies pertencentes a esta família destaca-se o sabugueiro (Sambucus australis Cham \& Schltdl.) nativo do Brasil, que apresenta vários potenciais econômicos, na parte farmacológica, através do uso na fabricação de chás para redução de peso, por apresentar o ácido ursólico, diminui os níveis de glicose e lipídeos do sangue (RAO et al., 2011), além do combate de piolhos (JORGE et al., 2009) e efeito antibacteriano (NASCIMENTO et al., 2014). Também apresenta potencial de inibidor na germinação de sementes de picão-preto (Bidens pilosa L.) (FORTES et al., 2009), guanxuma (Sida rhombifolia L.) (PICCOLO et al., 2007) e capim colonião (Panicum maximum Jacq.) (ROSA et al., 2007).

Sabendo-se de todo potencial empregado na planta de sabugueiro, surge-se a necessidade de buscar a melhor forma de multiplicar a espécie, devido a pequena quantidade de informações existentes na literatura sobre os melhores métodos e técnicas a serem utilizadas. Para o gênero Sambucus poucos são os estudos sobre a propagação das espécies, sendo uma das únicas citações literárias a da espécie $S$. nigra L. que a principal forma de propagação ocorre pela técnica de estaquia e a utilização de $1000 \mathrm{mg} \mathrm{L}^{-1}$ de AIB na forma de Fertimax 1000 e Sela Gel (JUNGLOS, 2013).

A estaquia é considerada uma técnica que apresenta inúmeras vantagens, como a manutenção das características genéticas da planta a ser propagada, além de ser considerada de fácil e rápida execução em relação as outras técnicas de multiplicação de plantas. Entretanto, algumas espécies apresentam dificuldades de enraizamento, fato que pode ocorrer devido a necessidade de um maior equilíbrio hormonal para a formação de radicelas, o que pode ser obtido a partir da aplicação exógena de reguladores de crescimento, como o ácido indolbutírico (AIB), que pode aumentar a concentração de auxina nos tecidos da planta, promovendo a aceleração do processo de formação radicular (FRANZON et al., 2004; BASTOS et al., 2006).

O tipo de estaca também pode influenciar diretamente no processo de multiplicação de plantas pelo método de estaquia, como foi verificado por Neves et al. (2006) em corticeira do mato, em que as estacas oriundas de mudas apresentaram um maior percentual de enraizamento. Já para a espécie Chamaecyparis lawsoniana P. as estacas apicais apresentam maiores percentuais de enraizamento (STUMPF et al., 2001). Tais estudos mostram o comportamento distinto de cada espécie em relação ao melhor tipo de estaca a ser utilizada.

Neste contexto, pouco se sabe sobre qual o melhor tipo de estaca a ser utilizada e a concentração de AIB ideal. Diante disso, este trabalho teve por objetivo avaliar a multiplicação do sabugueiro (Sambucus australis) de acordo com o tipo de estaca e concentração de ácido indolbutírico (AIB) pela técnica de estaquia.

\section{Material e Métodos}

O trabalho foi realizado na Unidade de Ensino e Pesquisa Horta de Plantas medicinais, da Universidade Tecnológica Federal do Paraná Câmpus Dois Vizinhos (PR).

O delineamento experimental foi inteiramente casualizado, em esquema fatorial 2 $x 5$ (tipo de estaca $x$ concentração de AIB), com 4 repetições de 10 estacas por unidade experimental.

Os ramos foram coletados de única planta, com idade de 5 anos (Figura 1A), na referida instituição, que estava em plena floração (Figura 1B). Ao serem retirados, os ramos foram colocados em água e mantidos a sombra para evitar sua oxidação. Estes foram preparados em estacas de $8 \mathrm{~cm}$, mantendo-se um par de folhas reduzido a $25 \%$ do tamanho original. As estacas foram preparadas de dois tipos de ramos Herbácea e Semi-lenhosa (Figura 1C), no entanto 
buscou-se manter um diâmetro médio de $1 \mathrm{~cm}$. $\mathrm{Na}$ base da estaca foi realizado corte em bisel e na extremidade superior corte perpendicular à estaca. Após a confecção das estacas estas foram colocadas novamente submersas em água para evitar a oxidação.

Figura 1. Planta de sabugueiro utilizada no trabalho (A), Planta de sabugueiro com flores (B), Estacas de sabugueiro prontas para serem colocadas nos tubetes (C), Estacas de sabugueiro já estaqueadas em tubetes de acordo com cada tratamento (D), Estacas de sabugueiro prontas para serem avaliadas (E) e Estacas de sabugueiro enraizadas (F).
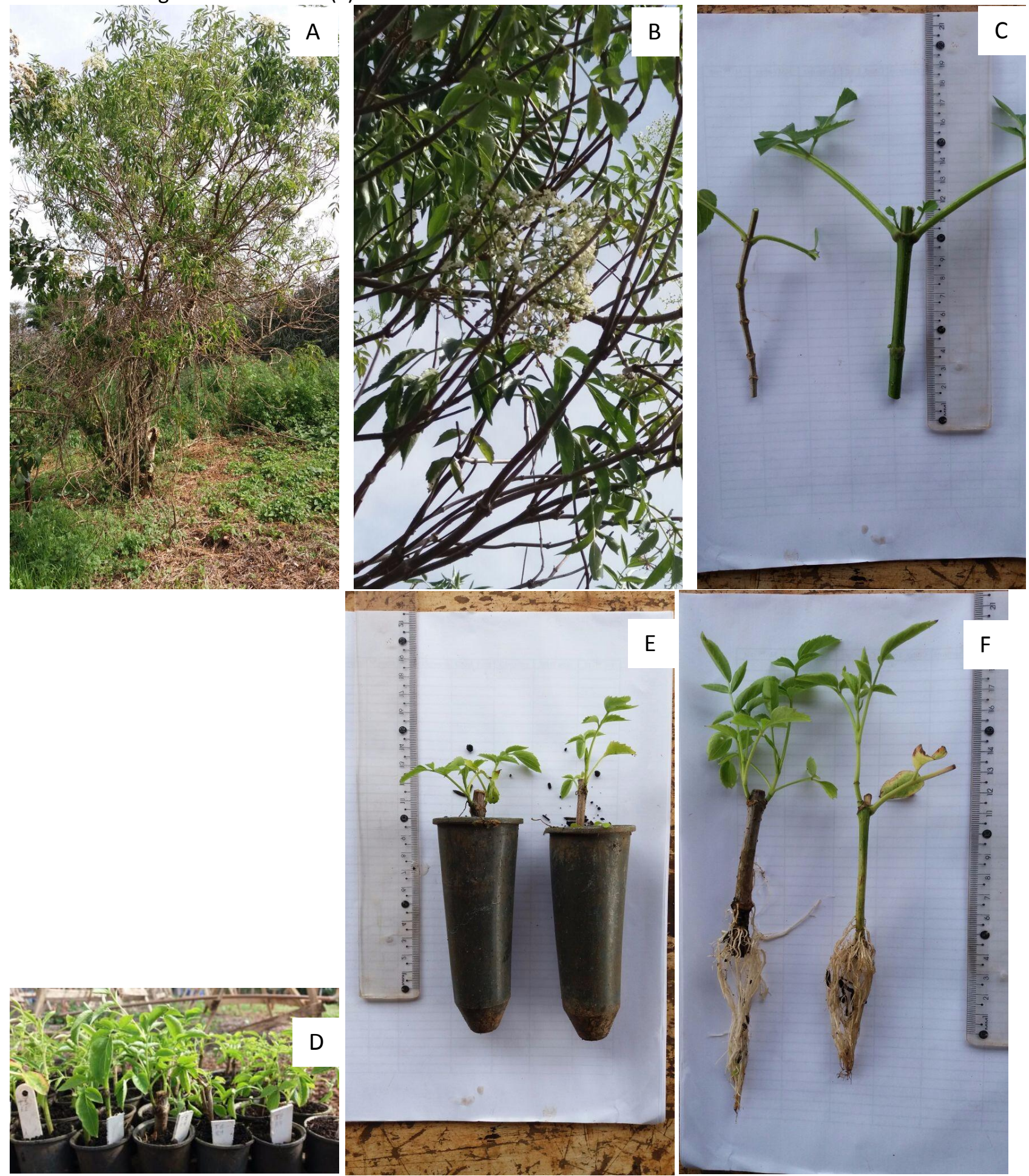
Em seguida, as bases das estacas foram tratadas com solução de AIB, com $99 \%$ de pureza, nas concentrações $0,500,1000,1500$ e $2000 \mathrm{mg}$ $\mathrm{L}^{-1}$, durante 10 segundos. As estacas foram colocadas em tubetes redondos $\left(163 \mathrm{~cm}^{3}\right)$ contendo substrato comercial MecPlant, tendose o cuidado de cobrir com o substrato cerca de $2 / 3$ do comprimento da estaca (Figura 1D). A irrigação foi realizada em dois períodos (no início da manhã e final da tarde), sempre verificando-se a umidade do substrato.

O AIB aplicado foi diluído em álcool, sendo que após esta diluição foi acrescentada água destilada na mesma proporção, formando-se solução com volume de 1:1 v/v (álcool + água destilada). Assim, foram preparadas 5 soluções, diferenciando-as somente na concentração diluída de AIB (HOSSEL et al., 2018).

Após 60 dias da implantação do experimento foram avaliados o enraizamento das estacas (\%) (presença de raízes com no mínimo 1 $\mathrm{cm})$, número médio de raízes por estaca, comprimento médio de raiz $(\mathrm{cm})$ (medição das 3 maiores raízes por estaca enraizada) (HOSSEL et al., 2018), número médio de brotações por estaca, comprimento médio das brotações $(\mathrm{cm})$, massa de matéria fresca (MMF) da parte aérea e radicular (g) (Verificação da massa imediatamente após a avaliação do experimento) e massa de matéria seca (MMS) da parte aérea e radicular (g) (Colocado em estufa a $65^{\circ} \mathrm{C}$ durante três dias, com a estabilização da massa) (COLOMBO et al., 2008) (Figura 1E e F).

Das estacas enraizadas, foram escolhidas aleatoriamente 5 , sendo replantadas em tubetes para avaliar a sobrevivência (\%) 30 dias após a avaliação e o restante foi separado em parte aérea e radicular e levado laboratório para verificação da massa de matéria fresca, as quais foram, posteriormente, colocadas em estufa a $65^{\circ} \mathrm{C}$ e mantidas por 3 dias. Ambas as massas foram obtidas em balança analítica.

Os dados das variáveis avaliadas foram previamente submetidos ao teste de Normalidade de Lilliefors, através do programa Genes . As transformações foram efetuadas por meio do arco-seno raiz de $x / 100$ e raiz quadrada de $x+1$ para variáveis que trabalham com unidades em percentual e valores observados, respectivamente. Com a transformação dos dados, os mesmos foram submetidos à análise de variância e ao teste de Duncan $(\alpha=0,05)$ para o fator qualitativo e de regressão para o quantitativo, com uso do programa Sanest (ZONTA; MACHADO, 1986).

\section{Resultados e Discussão}

Através dos resultados obtidos foi possível observar que houve interação significativa entre os fatores tipo de estaca $x$ concentração de AIB para a variável MMF da parte radicular (Tabela 1). Para as variáveis comprimento médio de raiz por estaca, número de brotação por estaca, comprimento médio de brotação e sobrevivência da estaca não observou-se diferenças significativas, as quais apresentaram as médias de $10,09 \mathrm{~cm} ; 1,67 ; 4,99 \mathrm{~cm}$ e $92,3 \%$, respectivamente.

Tabela 1. Massa de Matéria Fresca (MMF) da parte radicular das estacas de sabugueiro (Sambucus australis), de acordo com a concentração de AIB e o tipo de estaca.

\begin{tabular}{ccc}
\hline \multirow{2}{*}{ Concentração de AIB $\left(\mathrm{mg} \mathrm{L}^{-1}\right)$} & \multicolumn{3}{c}{ Tipo de Estaca } \\
\cline { 2 - 3 } & Herbácea & Semi-Lenhosa \\
\hline 0 & 1,10 a AB & 1,10 a A \\
500 & 1,51 a A & 1,41 a A \\
1000 & 1,34 a A & 1,27 a A \\
1500 & $1,00 \mathrm{~b} \mathrm{AB}$ & 1,73 a A \\
2000 & $0,75 \mathrm{~b} \mathrm{~B}$ & 1,67 a A \\
\hline CV (\%)* & &
\end{tabular}

*Médias seguidas pela mesma letra minúscula na linha e maiúscula na coluna não diferem entre si, pelo teste de Duncan $(\alpha=0,05)$.

**CV (Coeficiente de variação)

Ao analisar a MMF da parte radicular é possível verificar que nas concentrações de 1500 e $2000 \mathrm{mg} \mathrm{L}^{-1}$ de AIB as estacas semi-lenhosas apresentam maior massa em relação as herbáceas. Também é possível verificar que a MMF da parte radicular das estacas semilenhosas não foi influenciada pela concentração de AIB, entretanto para as estacas herbáceas a 
dose de $2000 \mathrm{mg} \mathrm{L}^{-1}$ afetou negativamente na MMF radicular (Tabela 1 ).

O aumento das concentrações de AIB influenciou negativamente na MMF da parte radicular das estacas herbáceas de modo que 0 ponto de maior massa foi encontrado na concentração de $750 \mathrm{mg} \mathrm{L}^{-1}$ com uma massa de 1,39 g (Figura 2C). Martins et al., (2001) também verificaram que o uso de dosagens maiores influenciou negativamente nas variáveis analisadas (enraizamento e comprimento radicular) para a espécie de jambeiro rosa (Syzygium malacensis).

Tal resultado pode ter ocorrido devido a espécie de sabugueiro apresentar uma boa adaptação ao uso da técnica de estaquia para multiplicação, já que mostrou-se autossuficiente na produção da quantidade de auxina necessária para a formação radicular, não necessitando da aplicação exógena. Diferentemente do que foi encontrado para algumas outras espécies como é o caso da Symphoricarpos microphyllus e pitaya vermelha ( $H$. undatus) que necessitam de 10000 e $3000 \mathrm{mg} \mathrm{L}^{-1}$ de AIB, respectivamente, para um bom enraizamento, sendo são consideradas altas dosagens (QUINTERO SÁNCHEZ et al., 2008; BASTOS et al., 2006).

Para o fator tipo de estaca de forma isolada foi possível observar significância para as variáveis número de raiz por estaca, MMF da parte aérea, MMS da parte aérea e MMS da parte radicular (Tabela 2 ).

$\mathrm{Na}$ Tabela 2 pode-se verificar que as estacas herbáceas apresentam maior número de raízes por estaca, fato que pode ser explicado pelas estacas com material mais jovem apresentar células mais jovens e com maior capacidade de diferenciação e formação de raízes adventícias, além de não apresentar nenhuma barreira na formação das raízes, como é o caso das estacas semi-lenhosas, que apresentam casca lignificada, o que se torna uma barreira para a emissão de raízes, fato também verificado na espécie de goiabeira (DANTAS et al., 1999), jabuticabeira (SASSO et al., 2010) e guabiroba (MARTINS et al., 2015) em que as estacas lenhosas não apresentam enraizamento ou o mesmo foi muito baixo.

Tabela 2. Número de raiz por estaca, Massa de Matéria Fresca (MMF) da parte aérea, Massa de Matéria Seca (MMS) da parte aérea e radicular das estacas de sabugueiro (Sambucus australis), de acordo com o tipo de estaca.

\begin{tabular}{ccccc}
\hline Tipo de Estaca & $\begin{array}{c}\text { Número de raiz/ } \\
\text { estaca }\end{array}$ & $\begin{array}{c}\text { MMF da parte } \\
\text { aérea }(\mathrm{g})\end{array}$ & $\begin{array}{c}\text { MMS da parte } \\
\text { aérea }(\mathrm{g})\end{array}$ & $\begin{array}{c}\text { MMS da parte } \\
\text { radicular }(\mathrm{g})\end{array}$ \\
\hline Herbácea & $24,60 \mathrm{~A}$ & $1,40 \mathrm{~B}$ & $0,17 \mathrm{~B}$ & $0,25 \mathrm{~B}$ \\
Semi-Lenhosa & $21,74 \mathrm{~B}$ & $2,49 \mathrm{~A}$ & $0,35 \mathrm{~A}$ & $0,59 \mathrm{~A}$ \\
\hline $\mathrm{CV}(\%)^{* *}$ & 15,19 & 14,96 & 8,57 & 9,37 \\
\hline
\end{tabular}

*Médias seguidas pela mesma letra não diferem entre si, pelo teste de Duncan $(\alpha=\leq 0,05)$.

**CV (Coeficiente de variação).

No entanto a MMF da parte aérea e MMS da parte aérea e radicular as estacas semilenhosas apresentam-se com resultados superiores (Tabela 2). O que pode ser explicado por estas estacas apresentarem maior quantidade de reserva e com o início da emissão de raízes estas conseguirem se desenvolver mais rapidamente em relação as herbáceas (OLIVEIRA et al., 2003).

Para o fator concentração de AIB isolado pode-se observar significância para as variáveis enraizamento (\%), número de raiz por estaca e MMF da parte radicular (Figura 2). O percentual de enraizamento foi afetado negativamente com a aplicação exógena de auxina apresentando um ponto de máxima com $379 \mathrm{mg} \mathrm{L}^{-1}$ de AIB, chegando a $96,9 \%$ de enraizamento (Figura $2 A$ ). Já para o maior número de raízes por estacas a concentração mais adequada foi de $1360 \mathrm{mg} \mathrm{L}^{-1}$ de AIB com cerca de 27 raízes por estaca (Figura 2B). Neste sentido foi possível verificar uma concentração pequena de AIB proporciona um percentual de enraizamento elevado, mas com a aplicação de uma maior concentração de AIB resulta em maior quantidade de raízes emitidas por estaca. 
Figura 2. Enraizamento (\%) (A), Número de raízes por estaca (B) e Massa da Matéria Fresca (MMF) da parte radicular das estacas herbáceas das estacas de sabugueiro (Sambucus australis), de acordo com a concentração de AIB.
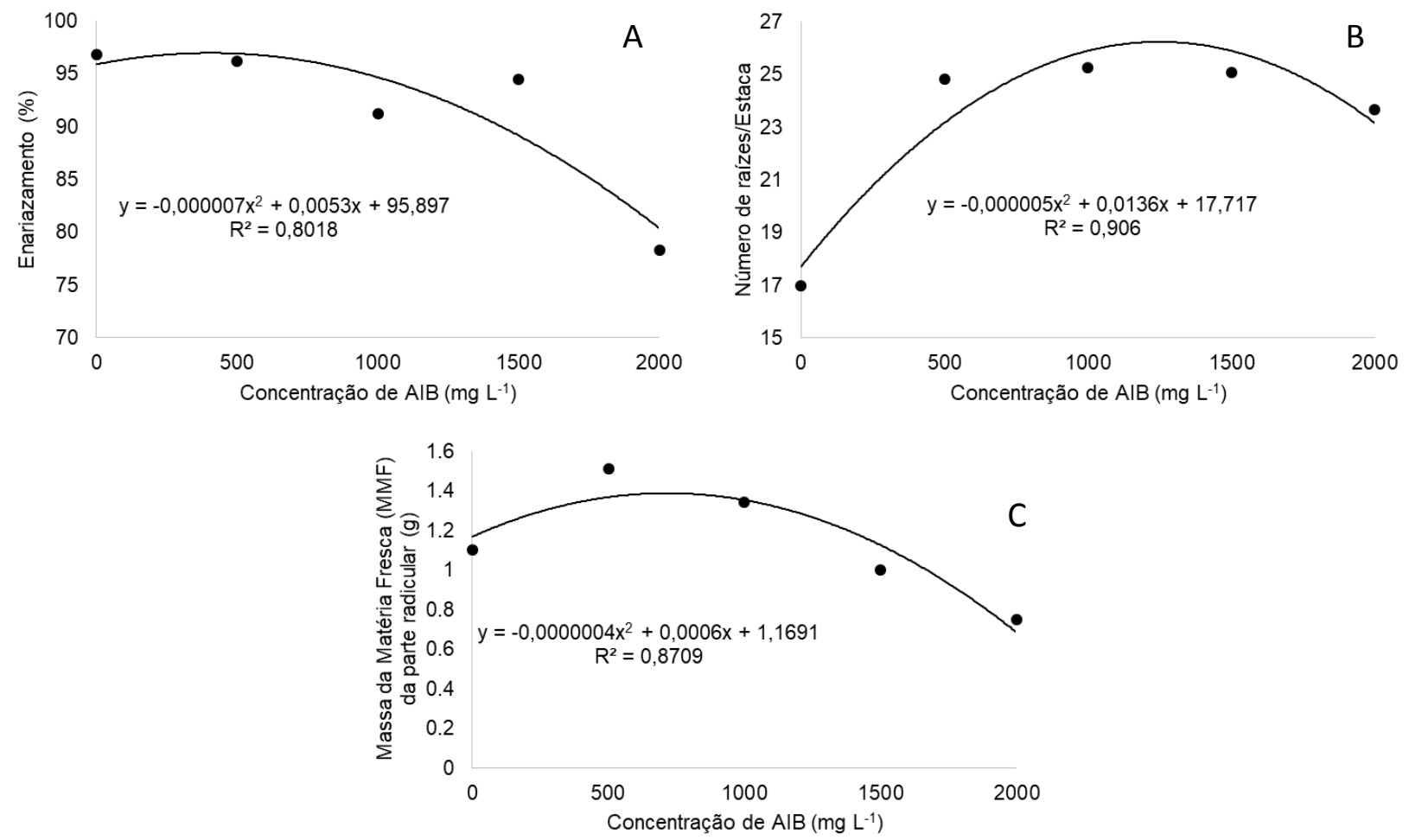

Resultados diferentes foram encontrados por Neves et al. (2006) com a espécie de corticeira-da-serra, e por Bastos et al. (2006) em estacas de pitaya, em que o aumento do percentual de enraizamento das estacas resultou, consequentemente no aumento do número de raízes.

$\mathrm{Na}$ Figura 2C, foi possível verificar que a massa de matéria fresca das raízes das estacas de sabugueiro, apresentaram maior resultado com a concentração de $750 \mathrm{mg} \mathrm{L}^{-1}$ de AIB, com média de 1,39 g por estaca.

A facilidade na propagação do sabugueiro pela técnica de estaquia, não necessitando de aplicações exógenas de AIB, pode ser explicado por ser a maneira correta a ser utilizada, além da redução do custo de produção e elevado rendimento na produção de mudas.

\section{Conclusão}

Para a multiplicação do sabugueiro (Sambucus australis) pela técnica de estaquia não é recomendada a aplicação exógena de auxina, de maneira que as estacas podem ser confeccionadas de material herbáceo e semilenhoso.

\section{Referência}

BASTOS, D. C.; PIO, R.; SCARPARE FILHO, J. A.; LIBARDI, M. N.; ALMEIDA, L. F. P.; GALUCHI, T. P. D.; BAKKER, S. T. Propagação da pitaya vermelha por estaquia. Ciência e Agrotecnologia, Lavras, v.30, n.6, p. 1106-1109, 2006.

https://doi.org/10.1590/S1413-

$\underline{70542006000600009}$

COLOMBO, L. A.; TAZIMA, Z. H.; MAZZINI, R. B.; ANDRADE, G. A.; KANAYAMA, F. S. BAQUERO, J. E.; AULER, P. A. M.; ROBERTO, S. R. Enraizamento de estacas herbáceas da seleção 8501-1 de goiabeira submetidas a lesão na base e a concentrações de AIB. Semina: Ciências Agrárias, Londrina, v.29, n.3, p. 539-546, 2008.

https://doi.org/10.5433/1679$\underline{0359.2008 v 29 n 3 p 539}$

DANTAS, A. C. M.; DUTRA, L. F.; KERSTEN, E. Influência do etefon e do tipo de estaca no enraizamento de goiabeira (Psidium guajava L.). Revista Brasileira de Agrociência, v.5, n.1, p. 1921, 1999.

HOSSEL, C.; WAGNER JÚNIOR, A.; HOSSEL, J. S. A. O.; FABIANE, K. C.; DALLAGO, A. Rooting of jabuticabeira of cabinhomini-cuttings (Plinia 
trunciflora). Comunicata Scientiae, v.9, n.4, p. 613-620, 2018.

FORTES, A. M. T.; MAULI, M. M.; ROSA, D. M.; PICCOLO, G.; MARQUES, D. S.; REFOSCO, R. M. C. Efeito alelopático de sabugueiro e capim-limão na germinação de limão na germinação de picãopreto e soja. Acta Scientiarum. Agronomy, Maringá, v.31, n.2, p. 241-246, 2009.

https://doi.org/10.4025/actasciagron.v31i2.718

FRANZON, R. C.; ANTUNES, L. E. C.; RASEIRA, M. C. B. Efeito do aib e de diferentes tipos de estaca na propagação vegetativa da goiabeira-serrana (Acca sellowiana Berg). Revista Brasileira de Agrociência, v.10, n.4, p. 515-518, 2004.

JORGE, T. C. M.; LENARTOVICZ V.; ANDRADE, M. W.; BONAFIN, T.; GIORDANI, M. A.; BUENO, N. B. C.; SCHNEIDER, D. S. L. G. Pediculicidal activity of hydroethanolic extracts of Ruta graveolens, Melia azedarach and Sambucus australis. Latin American Journal of Pharmacy, v.28, n.3, p. 457459, 2009.

JUDD, W. S.; CAMPBELL, C. S.; KELLOGG, E. A.; STEVENS, P. F.; DONOGHUE, M. J. Sistemática vegetal: um enfoque filogenético. 3. ed. Porto Alegre: Artmed, 2009. 612 p.

JUNGLOS, M. S. Propagação vegetativa de Sambucus nigra L. (Adoxaceae) pelo método de estaquia. In: ANAIS DO ENCONTRO DE INICIAÇÃO CIENTÍfICA, 5., 2013, Mato Grosso do Sul. Anais [...]. Mato Grosso do Sul: ENIC, 2013.

MARODIN, S. M.; BAPTISTA, L. R. M. Plantas utilizadas como medicinais no município de Dom Pedro de Alcântara, Rio Grande do Sul, Brasil. 1. Origem e aspectos ecológicos. Iheringia, Série Botânica, Porto Alegre, n.56, p. 131-146, 2001.

MARTINS, A. B. G.; GRACIANO, F. A.; SILVA, A. V. C. Clonagem do jambeiro-rosa (Syzygium malacensis) por estaquia de ramos enfolhados. Revista Brasileira de Fruticultura, Jaboticabal, v.23, n.2, p. 365-368, 2001.

MARTINS, W. A.; MANTELLI, M.; SANTOS, S. C.; NETTO, A. P.; PINTO, F. Estaquia e concentração de reguladores vegetais no enraizamento de Campomanesia adamantium. Revista de Ciências Agrárias, Lisboa, v.38, n.1, p. 58-64, 2015.
https://doi.org/10.1590/S0100$\underline{29452001000200033}$

NASCIMENTO, P. G. G.; LEMOS, T. L.; BIZERRA, A.; ARRIAGA, Â.; FERREIRA, D. A.; SANTIAGO, G. M.; BRAZ-FILHO, R.; COSTA, J. G. M. Antibacterial and antioxidant activities of ursolic acid and derivatives. Molecules, v.19, n.1, p. 1317-1327, 2014.

https://doi.org/10.3390/moléculas19011317.

NEVES, T. S.; CARPANEZZI, A. A.; ZUFFELLATORIBAS, K. C.; MARENCO, R. A. Enraizamento de corticeira-da-serra em função do tipo de estaca e variações sazonais. Pesquisa agropecuária brasileira, Brasília, v.41, n.12, p. 1699-1705, $2006 . \quad$ https://doi.org/10.1590/S0100$\underline{204 \times 2006001200003}$

NEWMAN, D. J.; CRAGG, G. M. Natural products as sources of new drugs from 1981 to 2014. Journal of Natural Products, v.79, n.3, p. 629661 ,

2016.

https://doi.org/10.1021/acs.jnatprod.5b01055.

OliveirA, A. P.; NIENOWI, A. A.; CAlVete, E. O. Capacidade de enraizamento de estacas semilenhosas e de cultivares de pessegueiro tratadas com AIB. Revista Brasileira de Fruticultura, Jaboticabal, v.25, n.2, p. 282-285, $2003 . \quad$ https://doi.org/10.1590/S0100$\underline{29452003000200025}$

PICCOLO, G.; ROSA, D. M.; SOMMER MARQUES, D.; MAULI, M. M.; TEIXEIRA FORTES, A. M. Efeito alelopático de capim limão e sabugueiro sobre a germinação de guanxuma. Semina: Ciências Agrárias, Londrina, v.28, n.3, p. 381-386, 2007.

https://doi.org/10.5433/1679-

0359.2007v28n3p381

QUINTERO SÁNCHEZ, A. I.; RODRÍGUEZ TREJO, D. A.; GUÍZAR NOLAZCO, E.; BONILLA BEAS, R. Propagación vegetativa de la vara de perlilla (Symphoricarpos microphyllus H.B.K.). Revista Chapingo, v.14, n.1, p. 21-26, 2008.

RAO, V. S.; MELO, C. L.; QUEIROZ, M. G. R.; LEMOS, T. L.; MENEZES, D. B.; MELO, T. S.; SANTOS, F. A. Ursolic acid, a pentacyclic triterpene from Sambucus australis, prevents abdominal adiposity in mice fed a high-fat diet. Journal of Medicinal Food, v.14, n.11, p. 1375- 
1382, 2011.

https://doi.org/10.1089/imf.2010.0267.

ROSA, D. M.; FORTES, A. M. T.; PALMA, D.; MARQUES, D. S.; CORSATO, J. M.; LESZCZYNSKI, R.; MAULI, M. M. Efeito dos extratos de tabaco, Leucena e Sabugueiro sobre a germinação de Panicum maximum Jaqc. Revista Brasileira de Biociências, Porto Alegre, v.5, supl.2, p. 444-446, 2007.

SASSO, S. A. Z.; CITADIN, I.; DANNER, M. A. Propagação de jabuticabeira por estaquia. Revista Brasileira de Fruticultura, Jaboticabal, v.32, n.2, p. 577-583, 2010. https://doi.org/10.1590/S0100-

$\underline{29452010005000054}$

SCOPEL, M.; NUNES, E. C. M.; SILVA, M. V.; VENDRUSCOLO, G. S.; HENRIQUES, A. T.; MENTZ, L. A. Caracterização farmacobotânica das espécies de Sambucus (Caprifoliaceae) utilizadas como medicinais no Brasil. Parte I. Sambucus nigra L. Revista Brasileira de Farmacognosia, v.17, n.2, p. 249-261, 2007. https://doi.org/10.1590/S0102$\underline{695 \times 2007000200020}$

STUMPF, E. R. T.; GROLLI, P. R.; SCZEPANSKI, P. H. Efeito do ácido indolbutírico, substrato e tipo de estaca no enraizamento de Chamaecyparis lawsoniana PARL. Revista Brasileira de Agrociência, v.7, n.2, p. 101-105, 2001.

ZONTA, E. P.; MACHADO, A. A. Sistema de análise estatística (SANEST). Pelotas: Instituto de Física e Matemática, UFPEL, 1986. 399 p. 